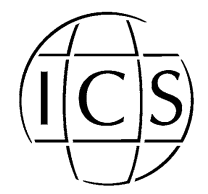

www.ics-elsevier.com

\title{
Y-chromosome haplotypes in East Timor (Timor-Leste): Evidences of population differentiation
}

\author{
L. Souto ${ }^{\mathrm{a}, \mathrm{b}, *}$, L. Gusmão $^{\mathrm{c}}$, E. Ferreira ${ }^{\mathrm{b}}$, A. Pires ${ }^{\mathrm{b}}$, A.M. Rocha ${ }^{\mathrm{b}}$, \\ A. Amorim ${ }^{\mathrm{c}, \mathrm{d}}$, F. Côrte-Real $^{\mathrm{e}}$, D.N. Vieira ${ }^{\mathrm{e}}$ \\ ${ }^{\text {a }}$ Centro de Biologia Celular, Departamento de Biologia, Universidade de Aveiro, Portugal \\ ${ }^{\mathrm{b}}$ Departamento de Biologia, Universidade de Aveiro, Aveiro, Portugal \\ ${ }^{\mathrm{c}}$ IPATIMUP, Instituto de Patologia e Imunologia Molecular da Universidade do Porto, Porto, Portugal \\ ${ }^{\mathrm{d}}$ Faculdade de Ciencias, Universidade do Porto, Porto, Portugal \\ e Delegação de Coimbra, Instituto Nacional de Medicina Legal, Coimbra, Portugal and Faculdade de Medicina \\ da Universidade de Coimbra, Portugal
}

\begin{abstract}
Haplotype frequencies were determined for 346 individuals from East Timor and 3 major ethnolinguistic groups were compared, putting in evidence the need for detailed analyses below the level of the major ethnolinguistic groups. Search of Timorese haplotypes matches in international databases returns few hits and almost all with Philippine data. (C) 2005 Published by Elsevier B.V.
\end{abstract}

Keywords: Y-chromosome; STR; East Timor; Timor-Leste; Southeast Asia

\section{Introduction}

The Y-chromosome markers, due to their peculiar characteristics, are considered useful tools in detecting populations' differentiation. The aim of the present study is to test possible correlations between ethnolinguistic information and genetic data, taking into account the generally assigned Austronesian or Papuan ancestry for the multiple Timorese ethnolinguistic groups, as national databases of forensic use may require specific substructuring. The search for matches with quality controlled international databases was also performed.

\footnotetext{
* Corresponding author. Departamento de Biologia, Universidade de Aveiro, Aveiro, Campus Universitário de Santiago, 3810-193, Portugal. Tel.: +351 234 370350; fax: +351 234426408.

E-mail address: 1souto@bio.ua.pt (L. Souto).
} 


\section{Materials and methods}

Samples from 346 unrelated blood donors representing several districts of East-Timor were collected on FTA ${ }^{\circledR}$ Cards and DNA extraction followed the Chelex protocol [1] using $1.2 \mathrm{~mm}$ punches.

The 12 Y-chromosome specific STRs (DYS19, DYS389I and II, DYS390, DYS391, DYS392, DYS393, DYS385, DYS437, DYS438 and DYS439) were amplified with PowerPlex ${ }^{\circledR}$ Y System kit (Promega Corporation), following the manufacturer's instructions, and analysed in ABI 310 automatic sequencers (Applied Biosystems) with the Genescan 2.1 Analysis software.

According to anthropological and linguistics information [2] samples were classified in three major linguistic groups: Group A ("Fabronic", $N=92$ ) and Group A1 ("Ramelaic", $N=130$ ), which together form the Timoric (Timorese-Austronesian) branch; and a third group (Group B, $N=124$ ) including languages that are related to a Trans-New Guinea phylum (Papuan) and supposed to represent aboriginal (pre-austronesian) signature.

In population comparisons by mean of Rst's genetic distances, DYS385 was not considered and the number of repeats in DYS389I was subtracted from DYS389II. Haplotype diversities were calculated according to Nei [3]. All statistical analyses used the ARLEQUIN software, version 2.000 [4].

The haplotypes found in East Timor were searched in the "YHRD-Y Chromosome Haplotype Reference Database" (http://www.ystr.org), release 16, for the "minimal haplotype".

\section{Results and discussion}

\subsection{Haplotype diversity in East Timor}

The number of different haplotypes, as well as those observed in only one sample, together with haplotype diversities, are displayed in Table 1, while Table 2 describes the most frequent haplotypes in the 3 subgroups under consideration. The highest haplotype diversity value was found in Group A, "Fabronic", while the "Papuan" group B showed the lowest value.

Comparison of the 3 samples suggests that the "Ramelaic" group differentiates from the "Fabronic" and "Papuan" ones (Rst values of $0.02710, P=0.00366$ and Rst of $0.05839, P=0.0000$, respectively). The "Ramelaic" group includes the major ethnoliguistic group in East Timor (Mambai).

These genetic results, while showing a high homogeneity of "Papuan" speaking populations, also suggest that the Papuan/Austronesian linguistic group is genetically heterogeneous and deeper analyses at ethnolinguistic sub-groups and geographic districts should be considered.

Table 1

Number of haplotypes and haplotype diversity values found for the three ethnolinguistic groups and in the total sample

\begin{tabular}{lllll}
\hline & Group A & Group A1 & Group B & Total \\
\hline No. of individuals & 92 & 130 & 124 & 346 \\
No. of different haplotypes & 73 & 96 & 79 & 218 \\
No. of unique haplotypes & 61 & 77 & 56 & 163 \\
Haplotype diversity & $0.9931 \pm 0.0032$ & $0.9926 \pm 0.0025$ & $0.9882 \pm 0.0031$ & $0.9952 \pm 0.0007$ \\
\hline
\end{tabular}

Group A: "Fabronic"; Group A1: "Ramelaic"; and Group B; Papuan. 
Table 2

Most frequent Y-haplotypes in East Timor (less than 5 individuals not shown)

\begin{tabular}{|c|c|c|c|c|c|c|c|c|c|c|c|c|c|c|c|}
\hline Haplotype & DYS391 & DYS389I & DYS439 & DYS389II & DYS438 & DYS437 & DYS19 & DYS392 & DYS393 & DYS390 & DYS385 & A & A1 & B & Total \\
\hline $179 \mathrm{TL}$ & 11 & 13 & 13 & 29 & 10 & 15 & 16 & 13 & 13 & 23 & $13-15$ & 0 & 7 & 0 & 7 \\
\hline $168 \mathrm{TL}$ & 11 & 13 & 13 & 30 & 10 & 14 & 13 & 11 & 13 & 22 & $15-17$ & 0 & 0 & 7 & 7 \\
\hline $298 \mathrm{TL}$ & 10 & 12 & 11 & 28 & 10 & 14 & 15 & 12 & 13 & 20 & $14-19$ & 5 & 2 & 0 & 7 \\
\hline $189 \mathrm{TL}$ & 10 & 14 & 12 & 29 & 10 & 14 & 14 & 14 & 14 & 23 & $13-20$ & 2 & 2 & 2 & 6 \\
\hline $285 \mathrm{TL}$ & 10 & 12 & 11 & 28 & 10 & 14 & 15 & 12 & 13 & 21 & $14-20$ & 1 & 0 & 5 & 6 \\
\hline $287 \mathrm{TL}$ & 10 & 14 & 11 & 29 & 10 & 14 & 14 & 14 & 14 & 23 & $13-19$ & 1 & 4 & 1 & 6 \\
\hline $31 \mathrm{TL}$ & 10 & 12 & 11 & 28 & 10 & 14 & 14 & 14 & 14 & 24 & $12-19$ & 2 & 4 & 0 & 6 \\
\hline $412 \mathrm{TL}$ & 10 & 12 & 13 & 29 & 9 & 14 & 14 & 14 & 13 & 24 & $12-12$ & 2 & 0 & 4 & 6 \\
\hline $16 \mathrm{TL}$ & 11 & 13 & 12 & 29 & 10 & 16 & 16 & 14 & 12 & 23 & $13-15$ & 0 & 1 & 5 & 6 \\
\hline $227 \mathrm{TL}$ & 10 & 13 & 11 & 31 & 9 & 14 & 14 & 13 & 12 & 25 & $12-14$ & 2 & 0 & 3 & 5 \\
\hline $301 \mathrm{TL}$ & 10 & 12 & 11 & 29 & 10 & 14 & 16 & 14 & 13 & 23 & $11-14$ & 2 & 3 & 0 & 5 \\
\hline $117 \mathrm{TL}$ & 10 & 13 & 12 & 29 & 10 & 16 & 17 & 14 & 12 & 23 & $13-16$ & 0 & 0 & 5 & 5 \\
\hline $123 \mathrm{TL}$ & 10 & 12 & 12 & 30 & 10 & 14 & 16 & 12 & 13 & 21 & $14-17$ & 0 & 0 & 5 & 5 \\
\hline
\end{tabular}

Group A: "Fabronic"; Group A1: "Ramelaic"; and Group B; Papuan.

\subsection{Searches within international database}

In general, as expected by the low content in Asian and Oceanic samples at the current state of YHRD database, the haplotypes found in East Timor do not match the reference Y database, even those with high frequencies. Considering only the "minimal haplotype", 22 individuals from Timor Leste match "Asian haplotypes"; 17 "European" and 7 "African" (5 out of the 7 individuals correspond to haplotypes from Réunion, an island situated in the Indic, known by Portuguese presence but also by its ethnic mix with Malay, while the other African matches are related with Guiné-Bissau, a former Portuguese colony).

\section{Acknowledgements}

We thank Fundação Oriente, the services of the Portuguese embassy, particularly the health clinic of Motael (Dr. ${ }^{\text {a }}$ Fernanda Santos), the Minister of Health of the Democratic Republic of Timor-Leste, the Universidade Nacional de Timor-Leste and specially the Timorese volunteers for their collaboration.

This work was partially supported by POCTI, Programa Operacional Ciência, from Fundação para a Ciência e Tecnologia.

\section{References}

[1] P.S. Walsh, D.A. Metzer, R. Higuchi, Chelex-100 as a medium for simple extraction of DNA for PCR-based typing from forensic material, BioTechniques 10 (1991) 506-513.

[2] G. Hull. personal communication.

[3] M. Nei, Molecular Evolutionary Genetics, Columbia University Press, New York, 1987.

[4] S. Schneider, D. Roessli, L. Excoffier, Arlequin Ver.2.000: A Software for Population Genetics Data Analysis, Genetics and Biometry Laboratory, University of Geneva, Switzerland, 2000. 